University of Nebraska - Lincoln

DigitalCommons@University of Nebraska - Lincoln

Nanoindentation characterization of deformation and failure of aluminum oxynitride

\author{
J. J. Guo \\ Tohoku University \\ K. Wang \\ Tohoku University \\ T. Fujita \\ Tohoku University \\ J. W. McCauley \\ US Army Research Laboratory \\ J. P. Singh \\ US Army International Technology Center \\ See next page for additional authors
}

Follow this and additional works at: https://digitalcommons.unl.edu/usarmyresearch

Part of the Operations Research, Systems Engineering and Industrial Engineering Commons

Guo, J. J.; Wang, K.; Fujita, T.; McCauley, J. W.; Singh, J. P.; and Chen, M. W., "Nanoindentation characterization of deformation and failure of aluminum oxynitride" (2011). US Army Research. 127. https://digitalcommons.unl.edu/usarmyresearch/127

This Article is brought to you for free and open access by the U.S. Department of Defense at DigitalCommons@University of Nebraska - Lincoln. It has been accepted for inclusion in US Army Research by an authorized administrator of DigitalCommons@University of Nebraska - Lincoln. 


\section{Authors}

J. J. Guo, K. Wang, T. Fujita, J. W. McCauley, J. P. Singh, and M. W. Chen 


\title{
Nanoindentation characterization of deformation and failure of aluminum oxynitride
}

\author{
J.J. Guo $^{\text {a }}$, K. Wang ${ }^{\text {a }}$, T. Fujita ${ }^{\text {a }}$, J.W. McCauley ${ }^{\text {b }}$, J.P. Singh ${ }^{\text {c }}$, M.W. Chen ${ }^{\text {a,d,* }}$ \\ ${ }^{a}$ WPI Advanced Institute for Materials Research, Tohoku University, Sendai 980-8577, Japan \\ ${ }^{\mathrm{b}}$ US Army Research Laboratory, Aberdeen Proving Ground, MD 21078, USA \\ ${ }^{\mathrm{c}}$ US Army International Technology Center, Tokyo 106-0032, Japan \\ ${ }^{\mathrm{d}}$ Department of Mechanical Engineering, Johns Hopkins University, Baltimore, MD 21218, USA
}

Received 4 August 2010; received in revised form 9 November 2010; accepted 12 November 2010

Available online 7 December 2010

\begin{abstract}
A systematic study of the mechanical deformation and failure of transparent ceramic aluminum oxynitride (AlON) has been conducted using a depth-sensitive nanoindentation technique combined with transmission electron microscopy (TEM) and Raman spectroscopy. Although discrete displacement bursts appear in the load-depth profiles at high applied forces, a detectable high-pressure phase transition has not been found by means of micro-Raman spectroscopy and TEM. Instead, a high density of dissociated $\langle 110\rangle$ dislocations can be observed underneath the nanoindenters, suggesting that extensive plastic deformation takes place in the brittle ceramic at high contact pressures. Moreover, nanoindentation-induced micro-cracks oriented along well-defined crystallographic planes can also be observed, consistent with the low fracture toughness of AlON evaluated by an indentation method using Laugier's equation.
\end{abstract}

(C) 2010 Acta Materialia Inc. Published by Elsevier Ltd. All rights reserved.

Keywords: Nanoindentation; Plasticity; Transmission electron microscopy; Fracture toughness

\section{Introduction}

Aluminum oxynitride (AlON) spinel ceramic can be used for a wide range of engineering applications because of its outstanding mechanical properties, low specific gravity, and broad electromagnetic transparency [1-3]. There is considerable interest in the use of AlON as a transparent armor ceramic against high impact pressures [4]. Shock loading and Kolsky-bar experiments suggest that the mechanical response of AlON under dynamic loading and high pressures involves detectable inelastic deformation that may result from dislocation plasticity, twinning or pressured-induced solid-state phase transitions [5-8]. Nevertheless, the underlying micro-mechanisms responsi-

\footnotetext{
* Corresponding author at: WPI Advanced Institute for Materials Research, Tohoku University, Sendai 980-8577, Japan. Tel.: +81 22217 5993.

E-mail address: mwchen@wpi-aimr.tohoku.ac.jp (M.W. Chen).
}

ble for the nonlinear phenomenon have not been fully understood to date.

It has long been supposed that ceramic plasticity may play an important role in the impact performance of the brittle materials [9-11]. Recently, a number of new experimental and theoretical studies have provided compelling arguments that the dynamic yielding and failure of high performance ceramics directly relate to the variety of inelastic deformation mechanisms by dislocation plasticity and twinning [5,12-14]. However, direct characterization of the ceramic plasticity is rather difficult since their brittle nature leads to fragmentation that may mix the plastic deformation with other inelastic behaviors, such as micro-cracking and stress-induced phase transitions $[9,10,12-15]$. Post-mortem characterization of recovered fragments frequently gives rise to controversial conclusions, mainly because of the unknown and uncontrollable loading experience of individual ceramic debris produced by dynamic tests. In view of the complicacy of the underlying micro-mechanisms of the actual deformation and 
damage of brittle ceramics at high pressures, indentation techniques that can produce self-confining stresses and high contact pressures underneath indenters can be employed to investigate the deformation and failure of brittle ceramics. The relationship between hardness and applied forces has been suggested as an important index of ceramic brittleness and plasticity $[11,16]$. In the present study, a technique of depth-sensitive nanoindentation combined with micro-Raman spectroscopy and transmission electron microscopy (TEM) is used to characterize the deformation and failure of AlON. Nanoindentation has been established as a powerful technique to characterize mechanical properties (hardness and elastic modulus) and fracture toughness at small scales, such as individual crystallites and grains, and the variation of these properties with penetration depth by analyzing load-depth profiles [17-20]. Moreover, the unusual changes in nanoindentation loaddepth profiles have been widely recognized as the indicators of structural phase changes that occur within indented materials during the tests. This application has even greater importance in experimental studies of material physics under high pressures. For example, the emergence of dislocation slip or twinning in $\mathrm{Al}_{2} \mathrm{O}_{3}, \mathrm{SiC}$ and $\mathrm{ZnO}$ [21-24] and the high-pressure phase transformations in $\mathrm{Si}$ and $\mathrm{Ge}[25,26]$ in nanoindentation tests can result in discontinuities in loaddepth profiles of these materials. With complementary micro-Raman spectroscopy, pressure-induced structural changes such as a solid-state phase transformation [27] or amorphization [28] can be readily ascertained.

In this study, the plastic deformation and failure of AlON have been investigated by nanoindentation with a Berkovichi indenter. Post-mortem Raman spectroscopy is performed to identify the potential structural phase transitions. Cross-sectional TEM specimens prepared by focused ion beam (FIB) milling are characterized to investigate the microstructural changes beneath the nanoindentation.

\section{Experimental}

The investigated $\mathrm{AlON}$ material with a nominal composition of $\mathrm{Al}_{23} \mathrm{O}_{27} \mathrm{~N}_{5}\left(35.7 \mathrm{~mol} . \% \mathrm{AlN}\right.$ and $64.3 \mathrm{~mol} . \% \mathrm{Al}_{2} \mathrm{O}_{3}$ ) was procured from Surmet Corporation (Burlington, MA). For microstructure characterization and nanoindentation tests, the sample surfaces of AlON were mechanically polished to a mirror finish and followed by thermal etching in flowing nitrogen atmosphere at $1200{ }^{\circ} \mathrm{C}$ for $30 \mathrm{~min}$. Nanoindentation experiments were performed using a dynamic micro-hardness tester (Shimadzu W201S) equipped with a Berkovich diamond indenter at maximum loads ranging from 25 to $700 \mathrm{mN}$. Post-indentation examination was performed using a micro-Raman spectrometer (Renishaw 1000 , UK) with an argon ion laser source (excitation wavelength of $514.5 \mathrm{~nm}$ ). The high-point of the laser spot is as small as about $1 \mu \mathrm{m}$. The cross-sectional TEM specimens of the deformed AlON samples were prepared by the liftout technique using a multi-beam focused ion beam (FIB) system (JEOL, JIB-4600F). A low dose of Ga ion beam was adopted in the final cutting process to minimize surface damage. The microstructures of the as-prepared and deformed samples were characterized with a JEOL JEM$2100 \mathrm{~F}$ transmission electron microscope operated at $200 \mathrm{kV}$ and a scanning electron microscope (SEM).

\section{Results and discussion}

\subsection{Microstructural characterization of as-received AlON}

Fig. 1 shows a SEM micrograph of the as-received AlON that has large grain sizes ranging from 150 to $200 \mu \mathrm{m}$. Secondary phases at grain boundaries and triple-junction points cannot be found by careful SEM characterization. However, micrometer-sized voids can occasionally be seen. Quantitative chemical analysis by SEM energy dispersive spectroscopy (EDS) was conducted to measure the chemical composition of the as-received sample. During the measurements, standard $\mathrm{Al}_{2} \mathrm{O}_{3}$ and $\mathrm{AlN}$ samples were used as the references and the average composition of the AlON was determined to be 9.1 at. $\% \mathrm{~N}, 49.1$ at. $\% \mathrm{O}$ and 41.8 at. $\% \mathrm{Al}$, which closely agrees with the nominal composition (Table 1).

TEM specimens were prepared with the FIB system. The sample shown in Fig. 2a is intentionally cut from a region across a grain boundary. Dislocations are rarely observed in the sample and twins cannot be found. High-resolution electron microscopy (HREM) was employed to characterize the atomic structure of the grain boundary (Fig. 2a). The lattice image shows that the grain boundary has a high mismatch angle. A very thin amorphous layer (2-3 atomic layers) along with a few crystallites can be found at the grain boundary (Fig. $2 \mathrm{~b}$ and c). The crystallites with a diameter of $\sim 2 \mathrm{~nm}$ have a crystal structure and lattice constant that are consistent with AlON. Chemical analysis by EDS also cannot identify obvious composition difference between the small crystals and AlON matrix. However, the crystal orientations of the crystallites are different from those of the grains at the two sides of the grain boundary. Moreover, the chemical composition of the amorphous layer is also very close to that of AlON. Thus, these interfacial phases are most likely introduced by transient liquid phase sintering used in the dense bulk sample fabrication. The liquid AlON at the interface as sintering aid may not be fully reacted with the solid $\mathrm{AlON}$ phase during sintering and the remaining liquid forms the crystallites and amorphous phase at the grain boundary during cooling. Similar to SEM observations, a few nanosized voids can be found from TEM micrographs. Fig. 2d shows a void with diameter of $\sim 5 \mathrm{~nm}$ within a crystal of AlON. It is interesting to note that the void has a hexagonal shape projected from a $\left\langle\begin{array}{llll}1 & 1 & 0\rangle\end{array}\right.$ zone direction and the facets of the voids are parallel to low-index $\left\{\begin{array}{lll}1 & 1 & 0\end{array}\right\}$ and $\left\{\begin{array}{lll}0 & 0 & 1\end{array}\right\}$ planes.

\subsection{Nanoindentation measurements}

Micromechanical tests were carried out using nanoindentation with maximum loads ranging from 25 to 

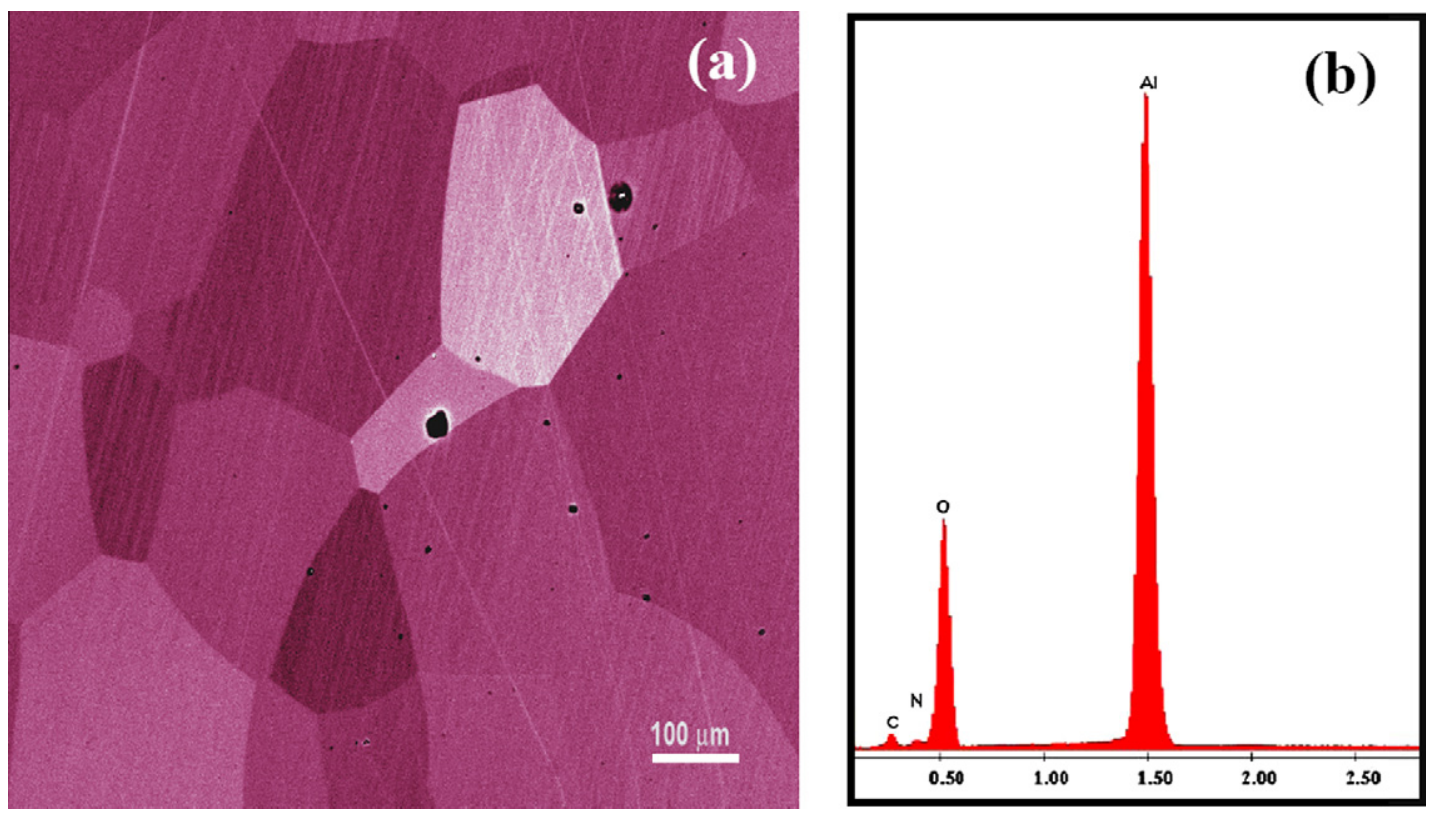

Fig. 1. (a) SEM micrograph of AlON showing grain sizes in the range of 150-200 $\mu \mathrm{m}$; and (b) corresponding quantitative EDS spectrum of AlON.

Table 1

Quantitative chemical analysis results of the as-received sample.

\begin{tabular}{lllll}
\hline Measurement & $\begin{array}{l}\text { Nitrogen } \\
\text { (at.\%) }\end{array}$ & $\begin{array}{l}\text { Oxygen } \\
\text { (at.\%) }\end{array}$ & $\begin{array}{l}\text { Aluminum } \\
\text { (at.\%) }\end{array}$ & $N_{\mathrm{N}} / N_{\mathrm{O}}$ \\
\hline$\# 1$ & 7.64 & 51.62 & 40.74 & 0.148 \\
$\# 2$ & 7.71 & 51.63 & 40.66 & 0.149 \\
$\# 3$ & 7.82 & 51.53 & 40.65 & 0.152 \\
Nominal & 9.1 & 49.1 & 41.8 & 0.185 \\
\hline
\end{tabular}

$700 \mathrm{mN}$. Fig. 3a shows the typical nanoindentation loaddepth profiles of AlON using a Berkovich indenter. The blue curve is the result of a small loading force $(150 \mathrm{mN})$ and the red one corresponds to a large loading force of $700 \mathrm{mN}$. It is evident that the load-depth profiles with the maximum loads smaller than $200 \mathrm{~nm}$ are smooth during the loading-unloading cycles and extensive plastic deformation can take place underneath the Berkovich
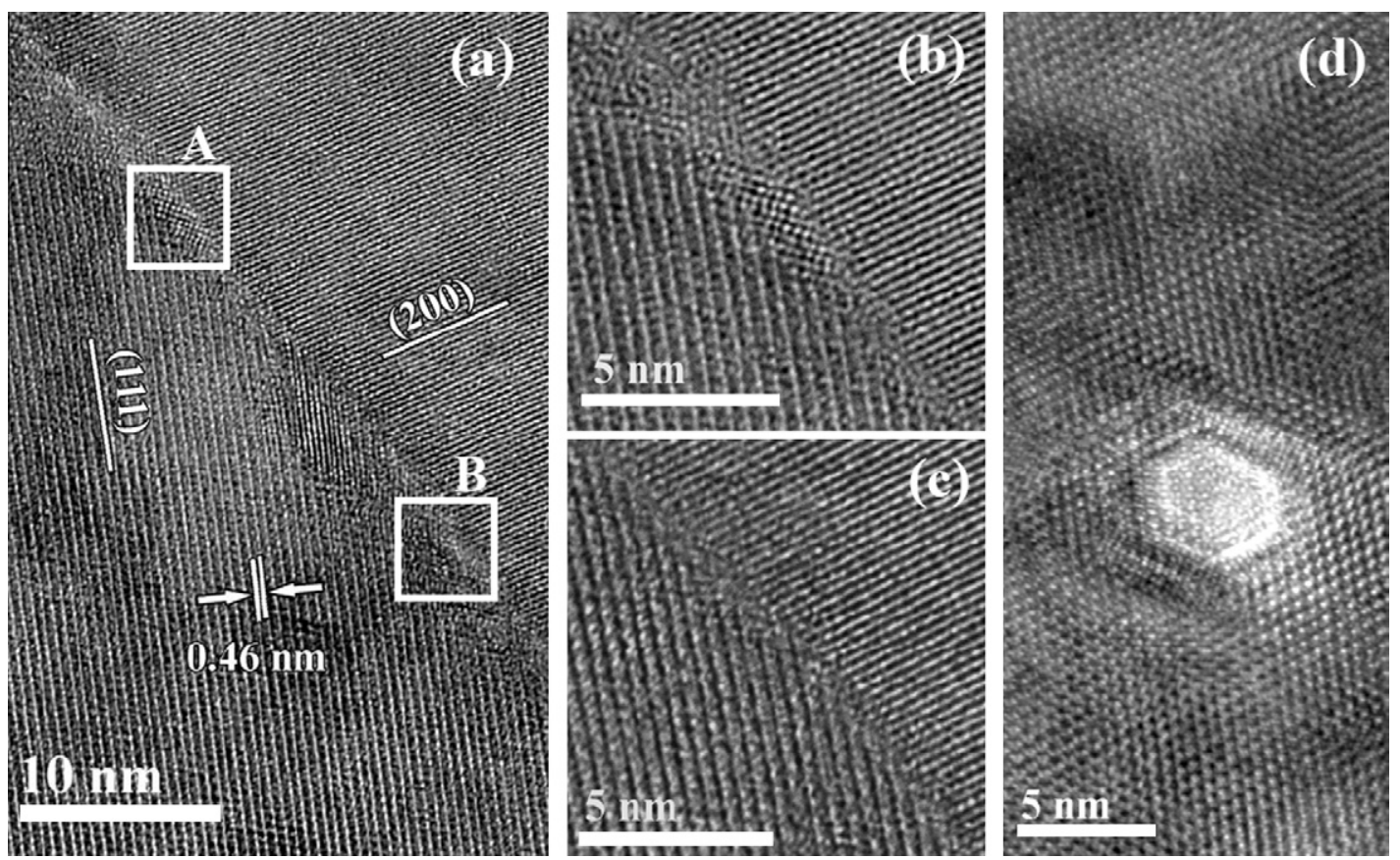

Fig. 2. HREM images of as-received AlON: (a) image taken from a region containing a high-angle grain boundary; (b and c) the magnified micrographs of area A and B in (a) showing a nano-sized AlON crystallites and amorphous layer in grain boundary; and (d) a void with diameter of $\sim 5 \mathrm{~nm}$ within a crystal of the polycrystalline AlON. 

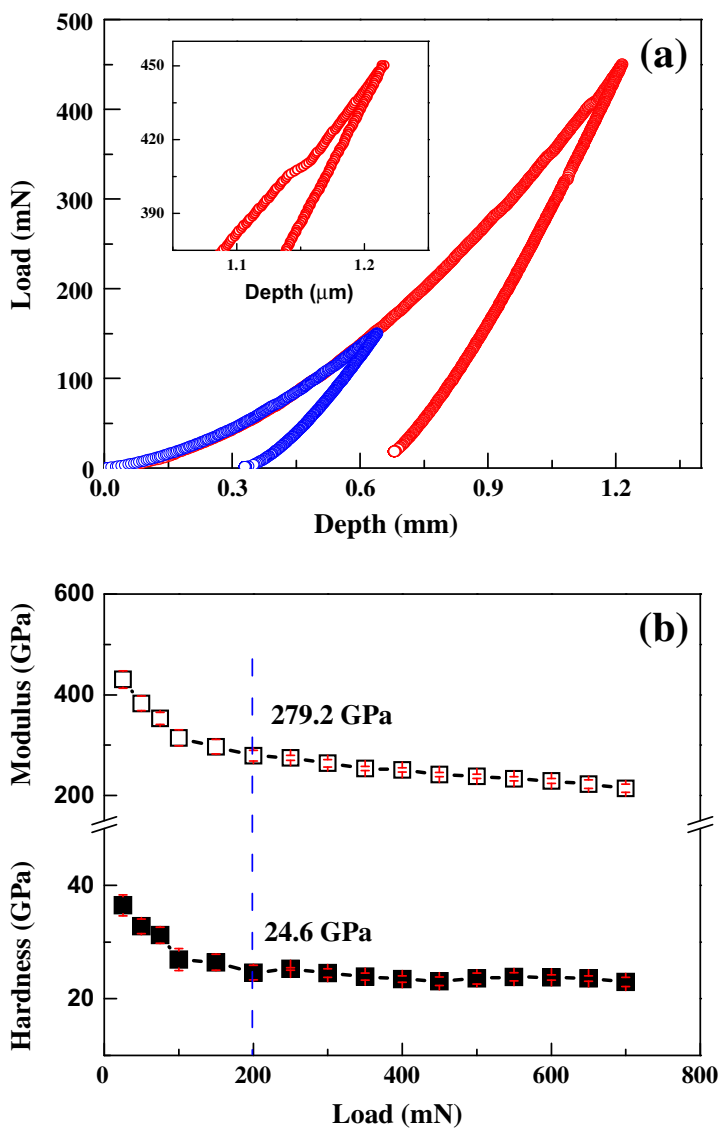

Fig. 3. (a) Typical nanoindentation load-depth curves of AlON with a Berkovich indenter. The results show discontinuities in loading process at larger loading forces. The inset is an enlarged portion the pop-in event. (b) The relationship between hardness/modulus and applied loads.

indenter without detectable cracking and phase transitions that may contribute to the inelastic displacements. However, when the maximum loads are larger than $200 \mathrm{mN}$, the load-depth profiles no longer keep smooth and discrete displacement bursts (so-called pop-ins) can be observed during loading. The inset of Fig. 3a is an enlarged portion highlighting a pop-in. The hardness and Young's modulus of AlON show strong dependence on the applied load and obviously decrease with increasing load and indent depth, particularly in the low force range. This may be associated with the size effect of the nanoindenter and the intrinsic plasticity $[4,29]$. The relationship between hardness/modulus and applied load is plotted in Fig. 3b. The hardness and Young's modulus at $200 \mathrm{mN}$ without detectable pop-ins in the load-depth curve are $\sim 24.6 \mathrm{GPa}$ and $279.2 \mathrm{GPa}$, respectively. On the other hand, the nanoindentation hardness is slightly higher than the micro-hardness (16-22 GPa) measured at high loading forces of above $1 \mathrm{~N}$. The Young's modulus well consists with the literature data determined by resonant ultrasound spectroscopy [4].

\subsection{Raman spectroscope analysis}

Since a pressure-induced solid-state phase transformation of $\mathrm{AlON}$ from a spinel-type structure to a $\mathrm{CaTi}_{2} \mathrm{O}_{4}$-type structure has been reported [8], the pop-in behavior in the load-depth profile of nanoindentation experiments may result from the first-order phase transitions that can cause significant volume changes [27]. To characterize the possible phase transition induced by nanoindentation, Raman microscopy was employed to characterize the microstructure of the indented regions. Fig. 4 shows Raman spectra acquired from a pristine region as well as from an indented region of AlON. The inserted SEM image shows the residual indentation produced with the maximum force of $200 \mathrm{mN}$. The dimension of the impression is $\sim 3 \mu \mathrm{m}$ along the longest direction, which is much larger than the $1 \mu \mathrm{m}$ laser spot. A laser power of $\sim 2 \mathrm{~mW}$ was adopted to avoid possible heating effects and sample damage. As shown in the curve A of Fig. 4, the Raman spectrum of cubic AlON is composed of a number of phonon modes at $304,397,626,747$, and $915 \mathrm{~cm}^{-1}$ in the range of $200-1200 \mathrm{~cm}^{-1}$. The origins of these phonon modes are not fully understood. Compared with the Raman spectrum of the as-received $\mathrm{AlON}$, the spectrum obtained from the center of the residual impression shows almost identical Raman peaks. Disappearance of AlON Raman bands and appearance of new bands cannot be found. Therefore, dramatic structure change or phase transitions in AlON do not seem to happen during the high-pressure nanoindentation experiment with the maximum contact pressure of $30 \mathrm{GPa}$. The only change that can be identified is that deformation makes the Raman peaks broader compared to that of the pristine one. Thus, deformation may lead to certain structure disorder as well as residual stress and strain and the pop-ins in the load-depth profiles of nanoindentation are most likely from micro-cracking or dislocation plasticity [24], but not from phase transitions.

\subsection{Fracture toughness measurements}

SEM characterization shows that micro-cracks appear at the corners of the residual indentations when the loading forces are larger than $200 \mathrm{mN}$, which coincides with the appearance of the pop-in events in the force-depth profiles. Thus, the discrete displacement bursts during nanoindentation experiments with large applied force are most likely

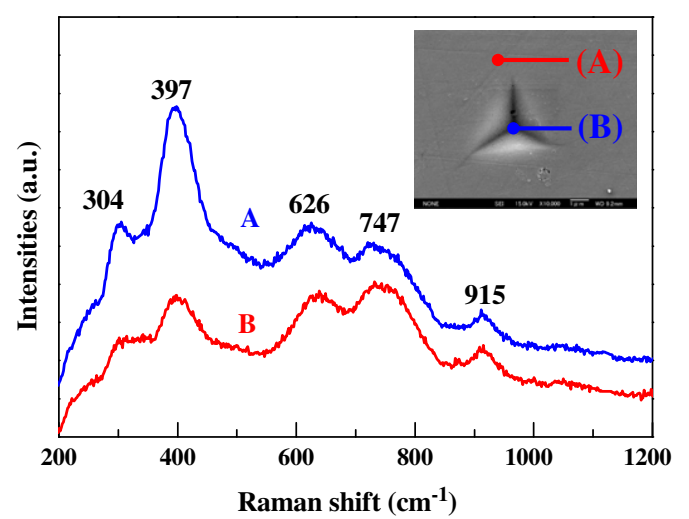

Fig. 4. Raman spectra of: (A) pristine AlON crystal and (B) indented AlON crystal (inserted SEM image shows the indented impression). 
caused by micro-cracking. Fig. 5 shows the representative SEM micrographs of the residual indentations at the maximum loads of $200 \mathrm{mN}, 300 \mathrm{mN}, 450 \mathrm{mN}, 700 \mathrm{mN}$, respectively. The micro-cracks become more distinct along with increased crack lengths at all three corners of the Berkovich indentations and can be easily observed at high maximum loads. However, the severe chipping or damage that usually occurs in very brittle materials [30] has not been observed in this study. Based on the crack length and the maximum loads, the fracture toughness of AlON can be measured by Berkovich nanoindentation using the following Eq. (1) [31]

$K_{c}=x_{V}\left(\frac{a}{l}\right)^{1 / 2}\left(\frac{E}{H}\right)^{2 / 3} \frac{P}{c^{3 / 2}}$

where $P$ is the maximum indentation load, $c$ is the crack length, $E$ is the Young's modulus and $H$ is the hardness. $\chi_{\mathrm{v}}$ was determined as 0.016 by Ouchterlony [32]. Values of $H$ and $E$ in Eq. (1) can be determined directly from the nanoindentation data using the method of Oliver and Pharr [33]. The crack length $c$ is measured from the indentation center to the tip of the emanated cracks as shown in Fig. 5e $[34,35]$. Since reliability of the measured fracture toughness values depends on the crack lengths and Eq. (1) works well only when cracks are shorter than $10 \mu \mathrm{m}$ [36], the maximum load used in this study is $700 \mathrm{mN}$ and at this force the crack length is less than $10 \mu \mathrm{m}$. A plot of fracture toughness vs. applied load is presented in Fig. 5e. In the low force range $(200-400 \mathrm{mN})$, there is a large scatter in the measured fracture toughness data because of the relatively large error in determining the lengths of short cracks. When the applied forces are larger than $400 \mathrm{mN}$, the measured values are very consistent and fall
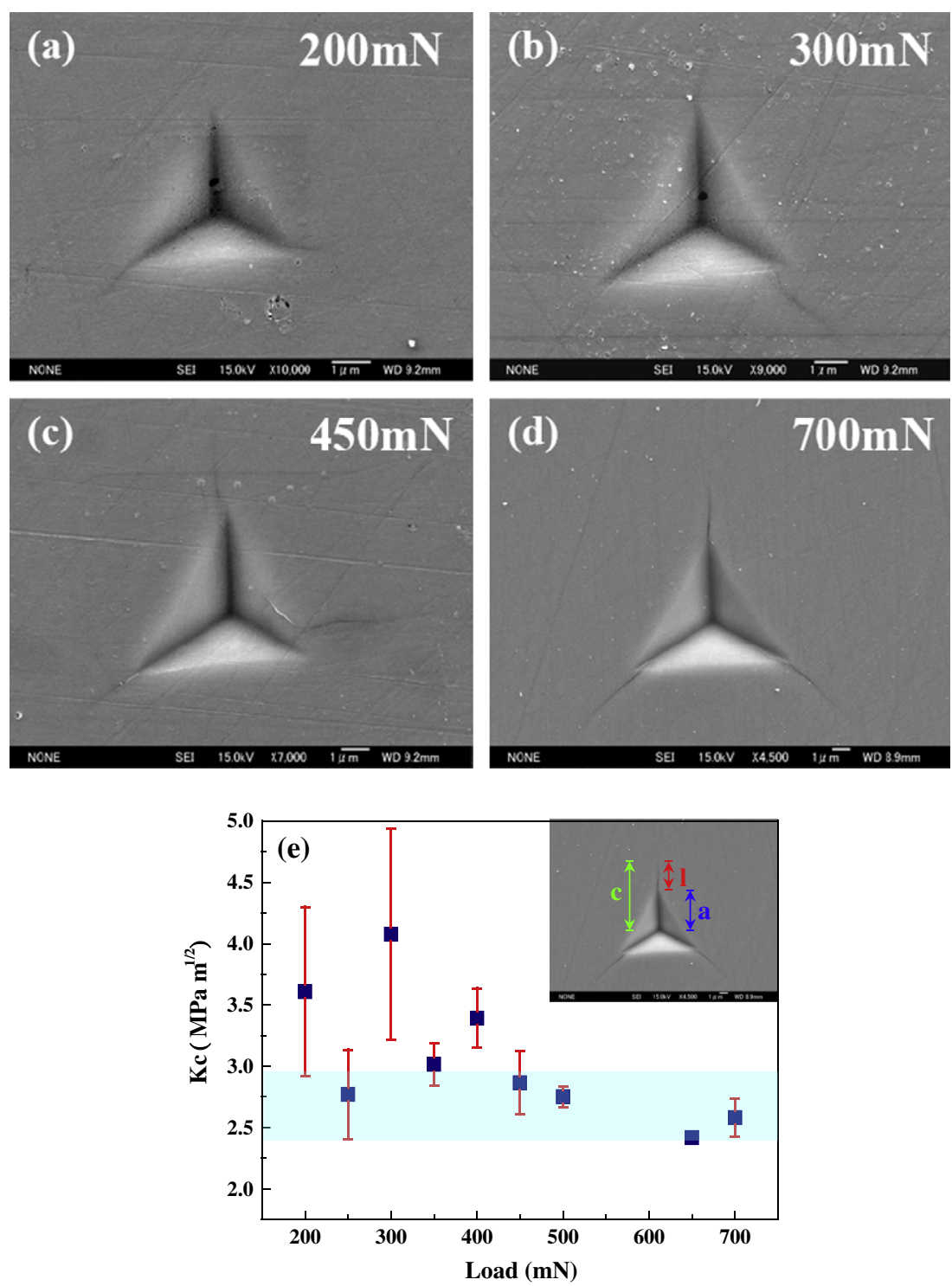

Fig. 5. (a-d) Representative SEM micrographs of nanoindentations made with various loading forces. Cracks at the corners of the indented impression can be observed. (e) Fracture toughness values as a function of applied forces. The shadow region represents the literature values. The insert is an SEM image of a Berkovich indenter impression showing the determination of the geometric parameters used in Eq. (1) for the calculation of fracture toughness: $a$ is the "contact radius", $c$ is the crack length, and $l$ is the crack length emanating from the indent corner. 


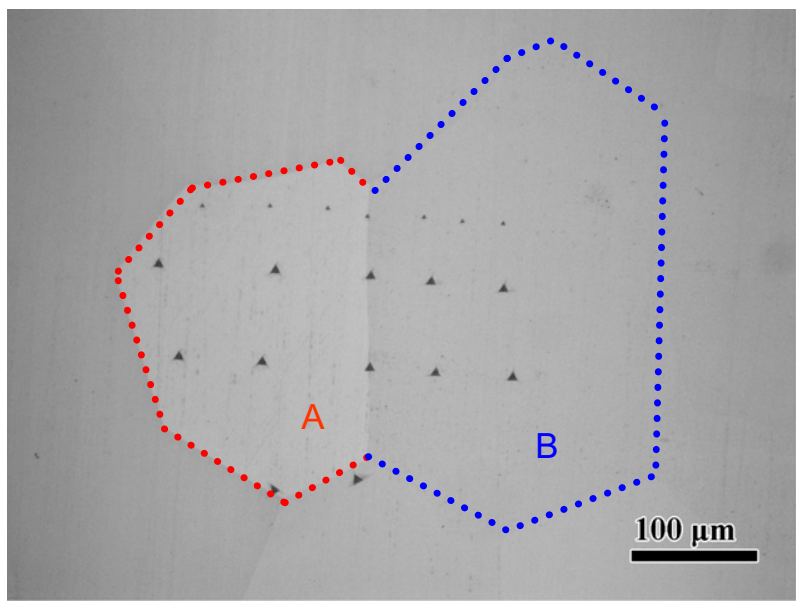

Fig. 6. Optical micrograph of two neighboring grains with residual indenters. Multiple indentation experiments with different load levels were accomplished in the two grains and the average mechanical properties were listed in Table 2.

Table 2

The mechanical properties of grain A and B in Fig. 6.

\begin{tabular}{lll}
\hline & Grain A & Grain B \\
\hline $\mathrm{E}(\mathrm{GPa})$ & $244.9 \pm 4.01$ & $288.3 \pm 0.75$ \\
$\mathrm{H}(\mathrm{GPa})$ & $2.74 \pm 0.85$ & $34.1 \pm 1.31$ \\
$\mathrm{Kc}\left(\mathrm{MPa} \mathrm{m}{ }^{1 / 2}\right)$ & $2.2 \pm 0.10$ & $1.5 \pm 0.02$ \\
\hline
\end{tabular}

in a narrow range between 2.4 and $2.9 \mathrm{MPa} \mathrm{m}^{1 / 2}$, which is in excellent agreement with the literature data [37].

Since the depth-sensitive nanoindentation has the capability to characterize mechanical properties at micrometer scales, the variation of hardness, Young's modulus and fracture toughness in two neighboring grains was investigated by multiple nanoindentation measurements at different load levels (Fig. 6). The measured hardness, Young's modulus and fracture toughness were averaged and listed in Table 2. The grain B has higher hardness (15.1\%) and Young's modulus (19.6\%) than the grain A whereas the soft grain A possesses higher fracture toughness. Although the AlON has a symmetric cubic structure, the obvious mechanical anisotropy may arise from the directional chemical bonding and resultant elastic anisotropy, which is intrinsically different from conventional cubic metals.

\subsection{Microstructural characterization of deformed AlON}

To explore the underlying micro-mechanisms of the deformation and failure of $\mathrm{AlON}$, the indented samples were subjected to TEM characterization. Cross-sectional TEM specimens sliced from residual impressions were prepared by a FIB system [38]. As illustrated in Fig. 7a-d, the selected region is cut from an impression and the TEM foil, formed by removing the surrounding matrix, has an orientation perpendicular to one ridge of the impression. The wedge-sharp sample is picked up by a tungsten microprobe and welded on to a copper grid. Finally, the sample is further thinned to a thickness of $\sim 30-50 \mathrm{~nm}$ by a low-energy ion beam with a small incidence angle. From these samples, the deformation areas underneath the impressions can be readily characterized by TEM. Fig. 8a is a bright-field TEM micrograph of the deformed AlON with the maximum load of $200 \mathrm{mN}$, in which high density
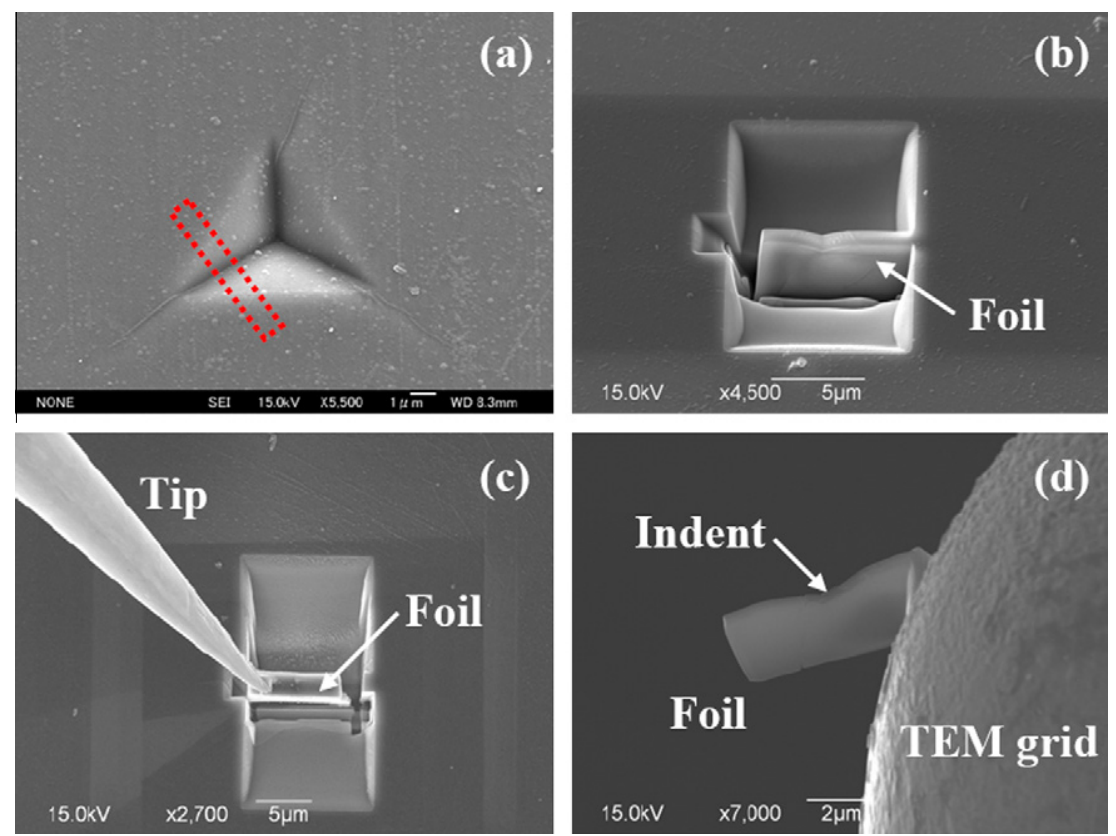

Fig. 7. Illustration of the typical procedure of cross-sectional TEM specimen preparation by FIB milling. (a) The selection of an imaging region from an indented impression; (b) two big trenches on both sides of the selected region made by FIB cutting; (c) lift out method of the TEM foil using a W tip; and (d) final thinning of the TEM foil by low-angle ion milling. 

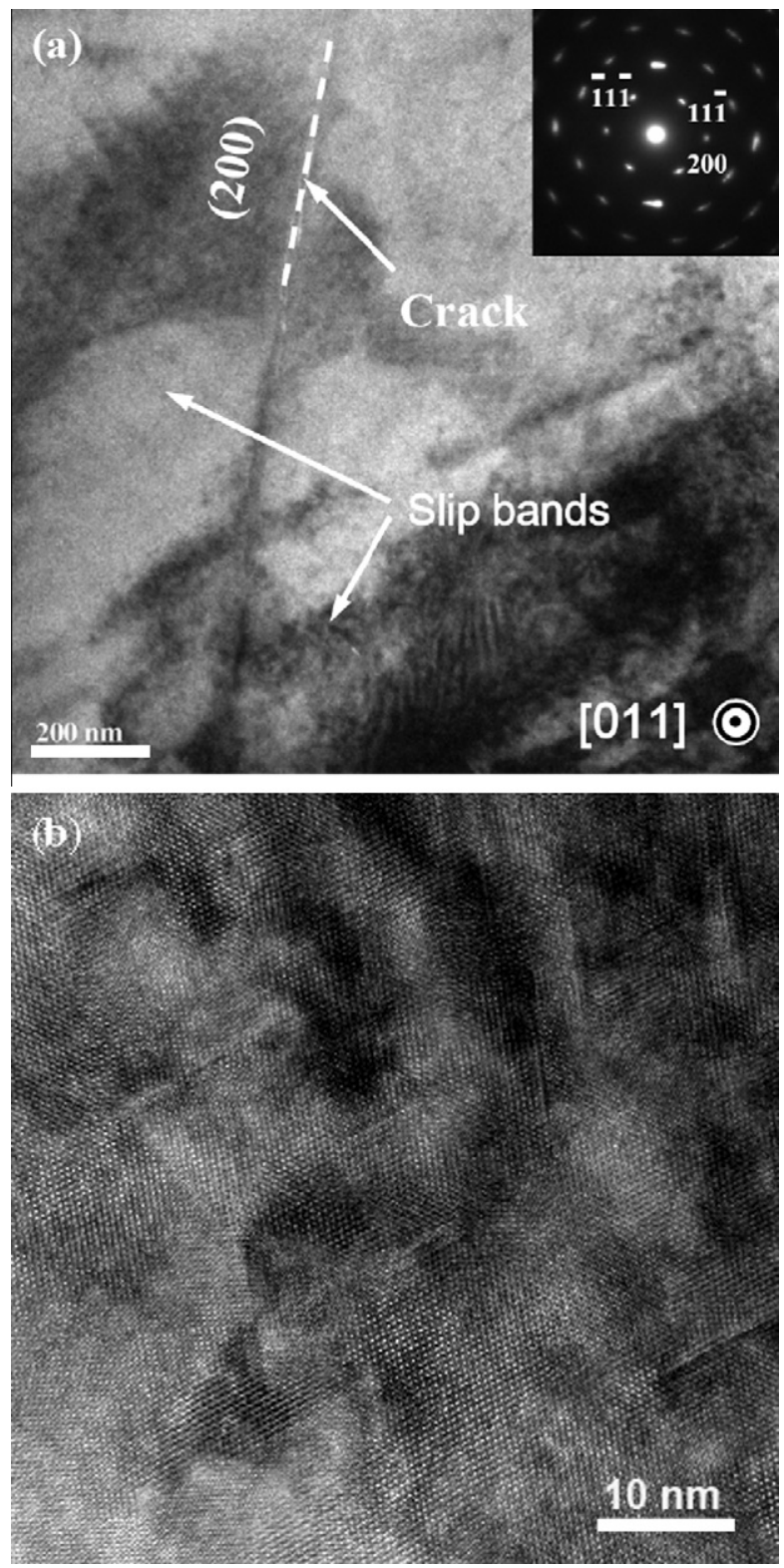

Fig. 8. (a) TEM image of the deformed area underneath the indenter. Inserted SAED pattern is taken from the deformed area. (b) Highresolution TEM image shows a disassociated dislocation on a $\left\{\begin{array}{lll}1 & 1 & 1\end{array}\right\}$ plane.

dislocations can be observed. Occasionally, a few microcracks can be found. A selected area electron diffraction (SAED) pattern along a $\left\langle\begin{array}{llll}0 & 1 & 1 & 1\end{array}\right.$ zone direction suggests that the deformed region underneath the indenter still holds the cubic AlON structure and a phase transition or amorphization cannot be seen. The arced diffraction spots in the SAED pattern indicate heavy lattice distortion of the deformed region, which may be associated with the high density of defects. Slip trace analysis suggests that the slip bands are approximately parallel to a $\left\{\begin{array}{lll}1 & 1 & 1\end{array}\right\}$ plane. The dislocation density in this region is estimated to be $\sim 2 \times 10^{15} \mathrm{~cm}^{-2}$, elucidating that AlON experiences extensive plastic deformation during nanoindentation at high
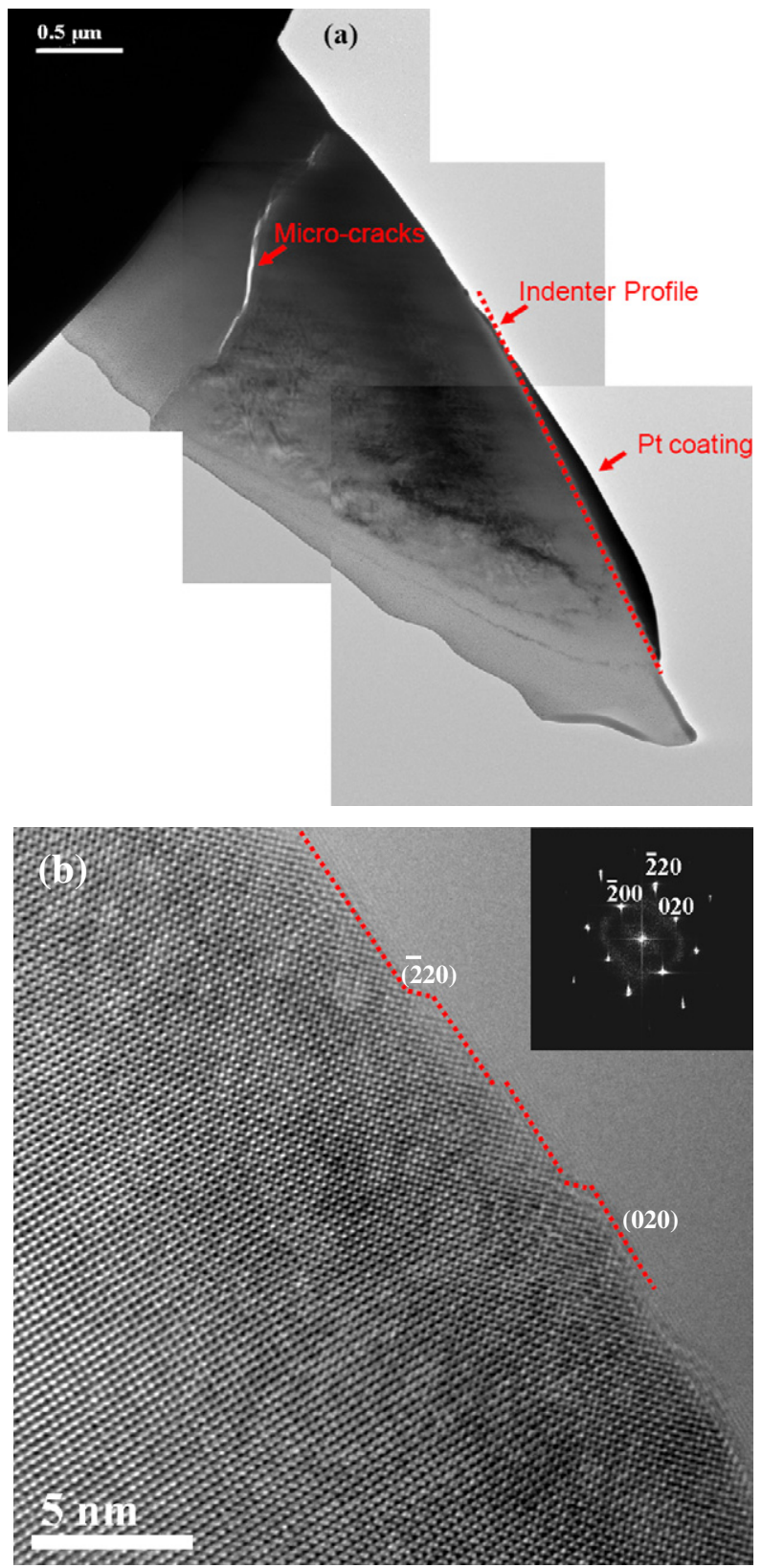

Fig. 9. (a) Bright-field TEM image of a TEM foil sliced from an indented impression made by $450 \mathrm{mN}$ applied force. Micro-cracks made by indentation experiment can be observed, mixed with dislocations. (b) High-resolution electron microscope image of the facet edges of the microcrack.

contact pressures and that the plastic deformation is mainly carried out by dislocations. HREM characterization reveals that the dislocations have a well-defined slip system (Fig. 8b). Burgers vector analysis confirms they are $1 / 2\left\langle\begin{array}{llll}1 & 1 & 0\end{array}\right\rangle$ dislocations on $\left\{\begin{array}{lll}1 & 1 & 1\end{array}\right\}$ planes, similar to ductile cubic metals. Moreover, the lattice images also show that the dislocations dissociate into two partial dislocations with a Burgers vector of $1 / 6\left\langle\begin{array}{llll}2 & 1 & 1\rangle\end{array}\right.$ along $\left\{\begin{array}{lll}1 & 1 & 1\end{array}\right\}$ planes with a core width of $\sim 10 \mathrm{~nm}$, suggesting AlON has a low stacking fault energy for the formation of partial dislocations and stacking faults at high pressures. 


\subsection{Cleavage vs. plasticity}

In addition to dislocations, well-developed micro-cracks mixed with the slip bands can be readily observed in deformed regions underneath the indenter when the applied stresses are larger than $200 \mathrm{mN}$. Fig. 9a shows an example in which micro-cracks can be observed in the sample loaded by a $450 \mathrm{mN}$ force during the nanoindentation experiment. In general, the micro-cracks have a sharp edge faceting on $\left\{\begin{array}{lll}0 & 0 & 1\end{array}\right\},\left\{\begin{array}{lll}1 & 1 & 0\end{array}\right\}$ or $\left\{\begin{array}{llll}1 & 1 & 1\end{array}\right\}$ planes, for example of Fig. 9b. Very few dislocations or stacking faults can be observed in the vicinity of fracture surface, suggesting that the failure of $\mathrm{AlON}$ is by cleavage along a low-energy crystallographic plane. Thus, the inelastic behavior of AlON during nanoindentation is quite complicated and includes both effects of plastic deformation and microcracking. Since AlON has a low fracture toughness of $\sim 2.4-2.9 \mathrm{MPa} \mathrm{m}^{1 / 2}$, it is intrinsically a brittle material and usually fails in a brittle manner without any plasticity when loaded under a uniaxial condition at ambient temperature. The extensive plastic deformation of AlON during nanoindentation apparently results from the confined stress state underneath the sharp pyramidal indenter, which can significantly suppress the cleavage failure that occurs at low stresses under uniaxial loading. Moreover, the small deformation volumes underneath indenter, particularly at low loading forces, may also play an important role in preventing the formation of micro-cracks. With the suppression of cracking, the material can stand high stresses that are above the critical value for the activation of dislocations. Since extensive plastic deformation takes place prior to the cleavage failure, the formation of micro-cracks may be associated with the dislocations. The intersection of slip systems may result in dislocation reactions and pile-up for the nucleation of micro-cracks [39], similar to the scenario described by the Stroh model for metallic materials [40].

\section{Conclusions}

Pressure-induced deformation and failure of a polycrystalline AlON ceramic have been systematically studied by using nanoindentation, SEM, TEM and Raman spectroscopy. The main results are summarized as follows:

(1) A detectable high-pressure phase transition of AlON subjected to nanoindentation experiments has not been observed by means of Raman microspectroscopy and TEM. The inelastic response during indentation mainly results from dislocation plasticity when the applied forces are smaller than $200 \mathrm{mN}$.

(2) Cross-sectional TEM micrographs show a high density of dislocations underneath indentations, suggesting extensive plastic deformation takes place at high pressures. The dislocations have been characterized as dissociated $\left\langle\begin{array}{llll}1 & 1 & 0\end{array}\right\rangle$ dislocations on $\left\{\begin{array}{lll}1 & 1 & 1\end{array}\right\}$ planes.
(3) At high loading forces, obvious cracking can be observed at the corners of residual impressions, which leads to the discrete displacement bursts in the load-depth curves of nanoindentation experiments. TEM observations indicate that the fracture facets of micro-cracks are along low-index crystallographic planes by cleavage.

(4) Fracture toughness was evaluated by measuring the crack length using SEM. The low fracture toughness of $\mathrm{AlON}\left(2.4-2.9 \mathrm{MPa} \mathrm{m}^{1 / 2}\right)$ indicates that AlON is an intrinsically brittle material. The extensive plastic deformation underneath the indenter results from the self-confining stress state and size effect of nanoindentation that can dramatically suppress the formation and propagation of micro-cracks and thereby enhance the plastic deformation of AlON.

\section{Acknowledgments}

This work is sponsored by "Global COE for Materials Research and Education", MEXT, Japan, US Army International Technology Center Pacific (ITC-PAC) of Tokyo, and US Army Research Lab through Johns Hopkins University.

\section{References}

[1] Corbin ND. J Eur Ceram Soc 1989;5:143.

[2] Cheng JP, Agrawal D, Zhang YJ, Roy R. J Mater Sci Lett 2001;20:77.

[3] Miller L, Kaplanw WD. J Am Ceram Soc 2008;91:1693.

[4] McCauley JW, Patel P, Chen MW, Gilde G, Strassburger E, Paliwal B, et al. J Eur Ceram Soc 2009;9:223.

[5] Paliwal B, Ramesh KT, McCauley JW, Chen MW. J Am Ceram Soc 2008;91:3619.

[6] Vaughn BAM, Proud WG, Field JE. Cavendish laboratory report. SP/1092; 2001.

[7] Paliwal B, Ramesh KT, McCauley JW. J Am Ceram Soc 2006;89:2128.

[8] Sekine T, Li X, Kobayashi T, Yamashita Y, Patel P, McCauley JW. J Appl Phys 2003;94:4803.

[9] Wilkins ML, Cline CF, Honodel CA. UCRL-71817; July 23, 1969.

[10] Lankford J et al. Mech Mater 1998;29:205-18.

[11] McCauley JW, Wilantewicz TE. In: Proceedings of the 26th army science conference, Orlando, Florida, ADM002187; December 1-4, 2008.

[12] Chen MW, McCauley JW, Dandekar DP, Bourne NK. Nat Mater 2006;5:614.

[13] Lundberg P, Lundberg B. Int J Impact Eng 2005;31:781-92.

[14] Bourne NK. Shock compression of condensed matter. In: AIP conference proceedings, vol. 1195; 2009. p. 993.

[15] Chen MW, McCauley JW, Hemker KJ. Science 2003;299:1563.

[16] Quinn JB, Quinn GD. J Mater Sci 1997;32:4331.

[17] Scharf TW, Deng H, Barnard JA. J Vac Sci Technol A 1997; 15:963.

[18] Oliver WC, Pharr GM. J Mater Res 2004;19:3.

[19] Fischer-Cripps AC. J Mater Res 2001;16:1579.

[20] Scholz T, Schneider GA, Munoz-Saldana J, Swain MV. Appl Phys Lett 2004;84:3055.

[21] Page TF, Oliver WC, McHargue CJ. J Mater Res 1992;7:450.

[22] Page TF, Riester L, Hainsworth SV. Mater Res Soc Symp Proc 1998;522:113. 
[23] Nowak R, Sekino T, Niihara K. Acta Mater 1999;47:4329.

[24] Basua S, Barsoum MW. J Mater Res 2007;22:2470.

[25] Weppelmann ER, Field JS, Swain MV. J Mater Res 1993;8:830.

[26] Gogotsi YG, Domnich V, Dub SN, Kailer A, Nickel KG. J Mater Res 2000;15:871.

[27] Yan XQ, Huang XM, Uda S, Chen MW. Appl Phys Lett 2005;87:191911.

[28] Yan XQ, Li WJ, Goto T, Chen MW. Appl Phys Lett 2006;88:131905.

[29] Greer JR, Oliver WC, Nix WD. Acta Mater 2005;53:1821.

[30] Jang J, Pharr GM. Acta Mater 2008;56:4458.

[31] Laugier MT. J Mater Sci Lett 1987;6:897.

[32] Ouchterlony F. Eng Fract Mech 1976;8:447.
[33] Oliver WC, Pharr GM. J Mater Res 1992;7:1564.

[34] Anstis GR, Chantikul P, Lawn BR, Marshall DB. J Am Ceram Soc 1981;64:533.

[35] Niihara K, Morena R, Hasselman DPH. J Mater Sci Lett 1983;2:221.

[36] Casellas D, Caro J, Molas S, Prado JM, Valls I. Acta Mater 2007;55:4277.

[37] Willems HX, Vanhal PF, Dewith G, Metselaar R. J Mater Sci 1993;28:6185.

[38] Wang K et al. Acta Mater 2008;56:3077.

[39] Buchs R, Basu S, Elshrief OA, Coward R, Barsoum MW. J Appl Phys 2009;105:093540.

[40] Stroh AN. Adv Phys 1957;6:418. 